\title{
Evaluation of Analgesic, Anti-Inflammatory, and Antipyretic Activity of Piperine: An Experimental Study
}

\author{
Nikhil Dhargawe, Sunil Mahakalkar, Bhagyashree Mohod, Jeffrey Pradeep Raj' \\ Department of Pharmacology, Government Medical College, Nagpur, 'Department of Clinical Pharmacology, Seth GS Medical College and KEM Hospital, Mumbai, \\ Maharashtra, India
}

\begin{abstract}
Background: Narcotics (e.g., opioids) or non-narcotics (e.g., salicylates and corticosteroids) are used in the management of pain and inflammation, both of which have side effects, thereby emphasizing the search for natural substances. Piperine found naturally in plants of the Piperaceae family has shown inhibitory activity against 5-lipoxygenase and cyclooxygenase-1 in in vitro studies. Objectives: To evaluate the analgesic, anti-inflammatory, and antipyretic activity of piperine in comparison to aspirin. Materials and Methods: Albino Wistar rats of either sex weighing 180-200 g and Swiss mice weighing 25-30 g were used. The tail-flick method and hot plate method in rats and acetic acid-induced writhing method in mice were used for the evaluation of analgesic activity. The carrageenan-induced paw edema method, cotton pellet-induced granuloma method, and formalin-induced arthritis method were used for the evaluation of anti-inflammatory activity. Baker's yeast-induced pyrexia model was used to evaluate antipyretic activity. Results: Piperine showed significant analgesic effect of $40 \%-55 \%$ in tail-flick method, $58 \%$ in hot plate method, and $54 \%$ in acetic acid-induced writhing model, when compared to negative controls. The percentage inhibition of inflammation, in comparison to controls, was significant at $56 \%$ for carrageenan-induced paw edema model and $40 \%$ for formalin-induced arthritis model. In the cotton pellet-induced granuloma model, however, it was only $10 \%$. In the yeast model of pyrexia, piperine significantly reduced rectal temperature at $4 \mathrm{~h}$. However, aspirin had better effect than piperine in all these models. Conclusion: Piperine exhibits significant analgesic, anti-inflammatory, and antipyretic activity though not comparable to aspirin.

Key words: Analgesic, anti-inflammatory, antipyretic, black pepper, Piper nigrum, piperine
\end{abstract}

\section{SUMMARY}

- We have demonstrated that piperine could be a potential analgesic anti-inflammatory, and antipyretic of natural origin that requires further evaluation in animal studies of larger sample sizes and different oral doses.
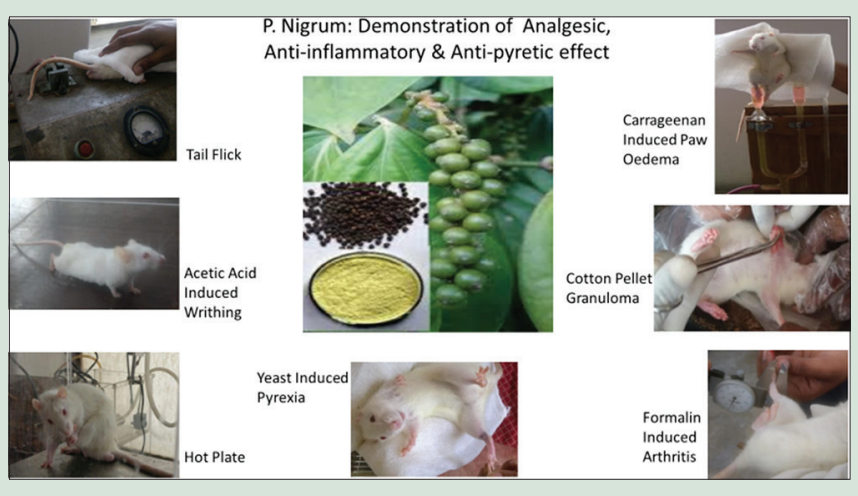

Abbreviations Used: IAEC: Institutional Animal Ethics Committee; CMC: Carboxymethyl cellulose; CPCSEA: Committee for the Purpose of Control and Supervision of Experiments on Animals; LCS: Linear cross-section; MPE: Maximum possible effect; SPSS: Statistical Package for the Social Sciences.

Correspondence:

Dr. Sunil Mahakalkar,

Department of Pharmacology, Government Medical College, Nagpur, Maharashtra, India. E-mail: drsunil_mm@rediffmail.com DOI: 10.4103/pr.pr_94_19

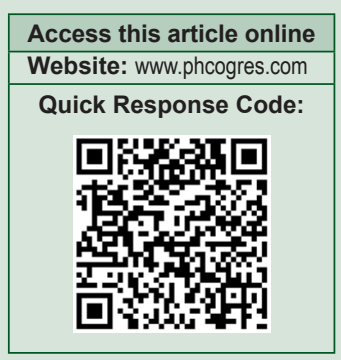

\section{INTRODUCTION}

Inflammation is defined as the reaction of living tissue to injury, and its cardinal signs include pain, swelling, redness, increased local warmth, and loss of function. ${ }^{[1]}$ Pain is defined as "an unpleasant sensory and emotional experience associated with actual or potential tissue damage or described in terms of such damage."[2] It is fundamentally a protective response, the ultimate goal of which is to help the organism get rid of both, the initial cause of injury (e.g., microbes and toxins) and the consequences of such injury (e.g., necrotic cells and tissues). Inflammation is of acute and chronic types. ${ }^{[1]}$ Acute inflammation is the immediate and early response to an injurious agent, while chronic inflammation is the inflammation of prolonged duration (weeks or months) in which there are active inflammation, tissue destruction, and attempts at repair, which proceed simultaneously. ${ }^{[1]}$ However, inflammation, if uncontrolled, can become a cause of suffering, leading to disabilities, contractures, disfiguring of body, and chronic pain. In such situations, the inflammation needs to be controlled or suppressed. ${ }^{[1]}$
Fever, on the other hand, is defined as the elevation of core body temperature above normal; in healthy adults, the average oral temperature is $37^{\circ} \mathrm{C}\left(98.6^{\circ} \mathrm{F}\right) .^{[3]}$ Although fever is beneficial, suppression of fever may be necessary for certain conditions, such as febrile convulsions, or to help alleviate discomfort and constitutional symptoms, such as fatigue, myalgias, diaphoresis, and chills. ${ }^{[3]}$ Drugs used for the management of pain and inflammation are either narcotics (e.g., opioids) or non-narcotics (e.g., salicylates and corticosteroids), both of which are well known for their side effects, such as intestinal tract ulcers

This is an open access journal, and articles are distributed under the terms of the Creative Commons Attribution-NonCommercial-ShareAlike 4.0 License, which allows others to remix, tweak, and build upon the work non-commercially, as long as appropriate credit is given and the new creations are licensed under the identical terms.

\section{For reprints contact: reprints@medknow.com}

Cite this article as: Dhargawe N, Mahakalkar S, Mohod B, Raj JP. Evaluation of analgesic, anti-inflammatory, and antipyretic activity of piperine: An experimental study. Phcog Res 2020;12:176-80. 
and erosions of the stomach linings. ${ }^{[4]}$ As a result, there is greater interest in finding a safer and potent alternative, especially agents from natural sources.

Piperine is an alkaloid found naturally in plants belonging to the Piperaceae family, such as Piper nigrum L. (black pepper) and Piper longum L. (long pepper). ${ }^{[5]}$ Black pepper is commonly used as a spice in the human diet and has been used in conventionally medicine as an analgesic and anti-inflammatory agent. ${ }^{[6]}$ Studies have also shown in vitro inhibitory activity against 5-lipoxygenase and cyclooxygenase- 1 of piperine. ${ }^{[7]}$ It also has cytoprotective, antioxidant, and neuroprotective effects. $^{[8]}$ Despite such vast pharmacological benefits, the scientific evidence on analgesic, anti-inflammatory, and antipyretic activities of piperine is limited. Hence, we proposed to evaluate these effects of piperine using appropriate validated animal models.

\section{MATERIALS AND METHODS}

\section{Ethics}

The study was conducted after approval from the Institutional Animal Ethics Committee (IAEC) of a Government Medical College, Maharashtra state, India, vide approval No. 2090-94 dated November 6, 2015. The IAEC is an approved body by the Committee for the Purpose of Control and Supervision of Experiments on Animals, New Delhi.

\section{Animals}

Albino Wistar rats of either sex weighing 180-250 g and Swiss mice weighing 25-30 g were used. The rats and mice were grouped in separate cages with six animals in each cage, and the floor was covered with husk. They were housed in the animal house at a temperature of $23^{\circ} \mathrm{C} \pm 2^{\circ} \mathrm{C}$, humidity of $40 \%-70 \%$, and acclimatized for 3 days. The photoperiod was $12 \mathrm{~h}$. The animals were fed standard pellet food and were given tap water ad libitum.

\section{Test substances}

Aspirin and carboxymethyl cellulose (CMC) were gifted by Alta Laboratories Limited (Mumbai, India). Piperine was received as a gift sample from Unijules Life Sciences Limited (Nagpur, India). Carrageenan ( $1 \%$ in $0.9 \%$ saline) and tramadol $(50 \mathrm{mg} / \mathrm{ml}$ ampule) were obtained from commercial sources.

\section{Preparation of solution of test substances}

$0.5 \%$ solution of CMC was prepared and homogenized using a magnetic stirrer. A $30 \mathrm{mg} / \mathrm{mL}$ solution of aspirin and $5 \mathrm{mg} / \mathrm{mL}$ solution of piperine were produced by homogenizing $300 \mathrm{mg}$ of aspirin and $50 \mathrm{mg}$ of piperine, respectively, in $10 \mathrm{~mL}$ of $\mathrm{CMC}$ solution.

\section{Dose calculation}

The required oral dose of aspirin was $300 \mathrm{mg} / \mathrm{kg}$ in rodents. ${ }^{[9]}$ Thus, for $30 \mathrm{~g}$ mice, the required dose of aspirin will be $9 \mathrm{mg}$ which converts to $0.30 \mathrm{~mL}$ of $30 \mathrm{mg} / \mathrm{mL}$ solution. The dose of aspirin in a $200 \mathrm{~g}$ rat would be $60 \mathrm{mg}$, which would convert to $2.0 \mathrm{~mL}$ of $30 \mathrm{mg} / \mathrm{mL}$ solution. In case of piperine, the required dose was $50 \mathrm{mg} / \mathrm{kg}$ in rodents. ${ }^{[6]}$ For a $30 \mathrm{~g}$ mice, the required dose will be $1.5 \mathrm{mg}$ which converts to $0.30 \mathrm{~mL}$ of $5 \mathrm{mg} / \mathrm{mL}$ solution of piperine in CMC vehicle. The dose of piperine in a $200 \mathrm{~g}$ rat would be $10 \mathrm{mg}$, which converts to $2.0 \mathrm{~mL}$ of $10 \mathrm{mg} / \mathrm{mL}$ solution of piperine in CMC.

\section{Experimental design}

For each of the experiments, 18 animals were randomized into three groups (control, standard, and test groups) of six animals each. No formal power calculation was done. The animals in the negative control group received the vehicle, $0.5 \% \mathrm{w} / \mathrm{v}$ CMC in orally. Aspirin in $0.5 \% \mathrm{w} / \mathrm{v}$ $\mathrm{CMC}$ vehicle was administered orally into the standard group at a dose of $300 \mathrm{mg} / \mathrm{kg}$, and piperine in $0.5 \% \mathrm{w} / \mathrm{v}$ CMC vehicle was given to the test group animals at a dose of $50 \mathrm{mg} / \mathrm{kg}$.

\section{Evaluation of analgesic activity ${ }^{[0]}$ \\ Tail-flick method in rats ${ }^{[10]}$}

After placing the rat in the analgesiometer, the middle part of the tail was exposed to heated nichrome wire that served as a radiant heat source with the strength of the electric current passing through the wire kept at 6 Amps. The endpoint was a "tail-flick response" which is characterized by a sharp withdrawal of the tail or a high-pitched noise called a squeak. The time to this response was recorded using a stopped clock as the "reaction time/latency." A cutoff time of $10 \mathrm{~s}$ was set as "maximum latency" to rule out thermal injury. The test was performed at baseline (basal latency) and at the end of 30,60, 90, and $120 \mathrm{~min}$ after drug administration (test latency). Percentage maximum possible effect (\%MPE; analgesia) was calculated using the formula: \%MPE $=([$ test latency - basal latency $] /[$ maximum latency - basal latency $])$ $\times 100$.

\section{Hot plate method in rats}

The rats were placed on a hot plate maintained at $55.0^{\circ} \mathrm{C} \pm 1^{\circ} \mathrm{C}$, and the endpoints were jumping, withdrawal, or licking of the paws. The time to endpoint was recorded as reaction time/latency. Basal latency was recorded before test drug administration, while test latency was recorded at $60,90,120$, and $180 \mathrm{~min}$ after drug administration, and \%MPE was calculated.

\section{Acetic acid-induced writing in mice}

Twisting or squirming movements of the body are seen in rodents during experimental induction of peritonitis. After habituation of mice for $30 \mathrm{~min}, 0.1 \mathrm{~mL}$ of $1 \%$ glacial acetic acid was injected intraperitoneally (IP) and was placed individually in transparent cages allowing $5 \mathrm{~min}$ to elapse. The number of writhes (stretching of the abdomen with simultaneous stretching of at least one hindlimb) was recorded over the subsequent $10 \mathrm{~min}$. Percentage inhibition was calculated using the formula ([mean number of writhing in the control group - mean number of writhing in the test group]/[mean number of writhing in the control group]) $\times 100$.

\section{Evaluation of anti-inflammatory activity ${ }^{[9]}$ Carrageenan-induced paw edema for acute inflammation ${ }^{[11]}$}

Paw edema was induced by an intradermal injection of $0.1 \mathrm{ml}$ of $1 \%$ carrageenan in normal saline into the plantar surface of the right hind paw of the rats. A plethysmometer was used to determine the volume of edema. All the drugs were administered $1 \mathrm{~h}$ before carrageenan injection, and readings were recorded before and at 60,120 , and $180 \mathrm{~min}$ after carrageenan injection. Percentage inhibition of paw edema was calculated using formula: ([mean paw volume in the control group - mean paw volume in test group]/[mean paw volume in the control group] $) \times 100$.

\section{Cotton pellet granuloma in rats for subacute inflammation}

Sterilized autoclaved cotton pellet weighing $50 \pm 1 \mathrm{mg}$, soaked in $0.2 \mathrm{~mL}$ of distilled water containing crystalline benzylpenicillin $0.1 \mathrm{mg}$ and streptomycin $0.13 \mathrm{mg}$, was implanted in the subcutaneous (SC) tissue of the right axilla of rats anesthetized under light ether anesthesia. The test drug was started 1 day before the insertion of cotton pellets and continued for 6 days. On the $7^{\text {th }}$ day, the granuloma containing the cotton pellets were dissected out carefully, dried overnight at $60^{\circ} \mathrm{C}$, and then weighed. The percentage anti-inflammatory effect was calculated using the formula ([mean increment in dry weight in control group - mean 
increment in dry weight in test group]/[mean increment in dry weight in the control group]) $\times 100$.

\section{Formalin-induced arthritis in rats for chronic inflammation}

Arthritis was induced by SC injection of $0.1 \mathrm{~mL}$ of $2 \%$ formalin under the plantar aponeurosis of the right hind paw of rats on the $1^{\text {st }}$ and $3^{\text {rd }}$ day of the experiment. The test drugs were given daily for 10 days. The linear cross-section (LCS) immediately below the ankle joint of right hind paw was measured daily with Vernier caliper and compared between days 1 and 10. Percentage anti-inflammatory effect was calculated using the formula: ([mean difference in LCS in control group - mean difference in LCS in test group]/[mean difference in LCS in control group] $) \times 100$.

\section{Evaluation of antipyretic activity ${ }^{[9]}$}

Animals were habituated for 2 consecutive days on rectal temperature measurement using a thermometer coated with glycerin. Pyrexia was induced in rats by administering freeze-dried Baker's yeast as 20\% suspension in $0.9 \%$ saline $(1 \mathrm{~g} / \mathrm{kg} \mathrm{SC})$ in the nape of the neck. Baker's yeast was administered $4 \mathrm{~h}$ before test drug administration, and the temperature was measured at $0,3,4$, and $6 \mathrm{~h}$ after drug administration and fall in temperature was compared between groups.

\section{Statistical analysis plan}

Data were entered using Microsoft Excel (Microsoft Corporation, Redmond, Washington, USA, 2016), and statistical analyses were performed using Statistical Package for the Social Sciences (SPSS) for Windows, Version 20.0 (IBM, Armonk, New York, USA, 2011). Friedman's test was used to compare different groups. If this test was statistically significant $(P<0.05)$, multiple comparisons were done using Mann-Whitney-U-test and the $P$ value for multiple comparisons was adjusted using Bonferroni's correction.

\section{RESULTS}

\section{Analgesic effect}

\section{Tail-flick method in rats}

The basal and test latency following treatment with $0.5 \% \mathrm{w} / \mathrm{v}$ CMC aspirin, tramadol, and piperine in tail-flick rat model is tabulated in Table 1 along with MPE\%. Piperine is significantly better than the control group at all-time points with MPE\% of around 40\%-55\%. However, when compared to aspirin or tramadol, piperine shows significantly less mean latency at all-time points except at $30 \mathrm{~min}$ where piperine and tramadol have an effect that is not different from each other.

\section{Hot-plate method in rats}

Table 2 depicts the basal and test latency following treatment with $0.5 \% \mathrm{w} / \mathrm{v} \mathrm{CMC}$, aspirin, and piperine in the hot plate model of nociception in rats along with MPE\%. Piperine has a significant favorable effect of approximately $39 \%, 58 \%$, and $80 \%$ at 90,120 , and $180 \mathrm{~min}$, respectively, when compared with the negative control group. However, aspirin was still better than piperine in increasing the latency period at 90 and $120 \mathrm{~min}$, while at 60 and $180 \mathrm{~min}$, both groups did not significantly differ from each other.

\section{Acetic acid-induced writing in mice}

Using this model, the mean (standard deviation [SD]) number of writhes over 10 min was 26.67 (1.21), 12.33 (1.51), and $7.83(0.75)$ in the control, aspirin, and piperine groups $(n=6$ in each group, $P<0.001)$. Percentage inhibition in comparison with control group was $70.61 \%$ for aspirin group $(P=0.004)$ and $53.54 \%$ for piperine group $(P=0.004)$, where the new significance level after Bonferroni's correction is set at $P<0.017$. However, aspirin was significantly better than piperine in reducing the number of writhes ( $P=0.004$ before Bonferroni's correction).

\section{Anti-inflammatory effect Carrageenan-induced paw edema for acute inflammation}

Table 3 shows that, at $1 \mathrm{~h}$, there is no difference between the three groups in the volume of paw edema. However, at 2 and $3 \mathrm{~h}$, piperine and aspirin show significantly lesser paw edema when compared to negative control group. When compared between aspirin and piperine group, there is no difference at $2 \mathrm{~h}$, but at $3 \mathrm{~h}$, piperine group has significantly higher paw edema than aspirin. The percentage inhibition at $3 \mathrm{~h}$ was $61.57 \%$ for aspirin group and $55.81 \%$ for piperine group when compared with the control group.

\section{Cotton pellet granuloma in rats for subacute inflammation}

The mean (SD) increment in dry weight of cotton pellet granuloma was 90 (12.65), 28.83 (5.38), and 81 (6.90) in the control, aspirin, and piperine group $(P=0.002)$. The percentage inhibition in comparison to controls is $67.96 \%$ for aspirin group $(P=0.004)$ and $10 \%$ for piperine group $(P=0.168)$ where the new significance level after Bonferroni's correction is set at $P<0.017$. The mean weight of granuloma was significantly less $(P=0.004$ before correction) when compared to piperine group.

\section{Formalin-induced arthritis in rats for chronic inflammation}

The mean (SD) of difference in LCS between days 1 and 10 was $2.01(0.06), 0.69(0.14)$, and $1.26(0.10)$, respectively, for the control,

Table 1: Effect of test substances in tail-flick model of analgesia in rats

\begin{tabular}{|c|c|c|c|c|c|}
\hline \multirow{2}{*}{$\begin{array}{l}\text { Groups } \\
\text { (n=6/group) }\end{array}$} & \multirow{2}{*}{$\begin{array}{c}\text { Basal latency, } \\
\text { mean } \pm S D\end{array}$} & \multicolumn{4}{|c|}{ Test latency at various time points, mean $\pm S D$} \\
\hline & & At $30 \mathrm{~min}$ & At $60 \mathrm{~min}$ & At $90 \mathrm{~min}$ & At $120 \mathrm{~min}$ \\
\hline \multicolumn{6}{|l|}{ Control } \\
\hline Seconds & $2.52 \pm 0.32$ & $2.44 \pm 0.24$ & $2.40 \pm 0.17$ & $2.33 \pm 0.12$ & $2.30 \pm 0.13$ \\
\hline Seconds & $2.61 \pm 0.18$ & $8.73 \pm 0.29$ & $7.78 \pm 0.13$ & $6.79 \pm 0.12$ & $6.77 \pm 0.23$ \\
\hline$\% \mathrm{MPE}$ & - & $82.77 \pm 3.80$ & $69.97 \pm 1.99$ & $56.53 \pm 1.54$ & $56.24 \pm 3.25$ \\
\hline \multicolumn{6}{|l|}{ Tramadol } \\
\hline \multicolumn{6}{|l|}{ Piperine } \\
\hline Seconds & $2.57 \pm 0.27$ & $6.52 \pm 0.22$ & $6.71 \pm 0.26$ & $5.50 \pm 0.37$ & $5.47 \pm 0.35$ \\
\hline$\% \mathrm{MPE}$ & - & $53.14 \pm 2.81$ & $55.69 \pm 3.26$ & $39.22 \pm 6.90$ & $48.16 \pm 10.48$ \\
\hline
\end{tabular}

$P<0.001$ between all four groups at all-time points except baseline $(P=0.565)$; baseline excluded for subsequent multiple comparisons. $P=0.004$ (without correction) for multiple comparisons, namely aspirin versus control, tramadol versus control, piperine versus control, aspirin versus piperine, and aspirin versus tramadol at all-time points except baseline. $P=0.004$ (without correction) between tramadol and piperine group at all time points except baseline and at $30 \mathrm{~min}(P=0.423)$. $P$ values based on actual latency period in seconds and statistical significance for multiple comparisons after Bonferroni's correction is set at $P<0.008$. SD: Standard deviation; \%MPE: Percentage maximum possible effect 
NIKHIL DHARGAWE, et al.: Analgesic, Anti-Inflammatory, and Antipyretic Activity of Piperine

Table 2: Effect of test substances on nociception in hot plate method in rats

\begin{tabular}{|c|c|c|c|c|c|}
\hline \multirow{2}{*}{$\begin{array}{l}\text { Groups } \\
\text { ( } n=6 / \text { group) }\end{array}$} & \multirow{2}{*}{$\begin{array}{c}\text { Basal latency, } \\
\text { mean } \pm S D\end{array}$} & \multicolumn{4}{|c|}{ Test latency at various time points, mean \pm SD } \\
\hline & & At $60 \mathrm{~min}$ & At $90 \mathrm{~min}$ & At $120 \mathrm{~min}$ & At $180 \mathrm{~min}$ \\
\hline \multicolumn{6}{|l|}{ Control } \\
\hline Seconds & $12.79 \pm 0.82$ & $11.70 \pm 1.90$ & $12.40 \pm 0.52$ & $12.49 \pm 0.74$ & $12.50 \pm 0.56$ \\
\hline Seconds & $12.42 \pm 2.08$ & $16.04 \pm 3.02$ & $23.07 \pm 3.65$ & $27.34 \pm 1.15$ & $27.68 \pm 0.96$ \\
\hline \%MPE & - & $21.02 \pm 9.94$ & $61.71 \pm 15.88$ & $85.30 \pm 0.05$ & $86.41 \pm 6.83$ \\
\hline \multicolumn{6}{|l|}{ Piperine } \\
\hline
\end{tabular}

$P=0.849$ between all 3 groups at baseline; 0.01 at $60 \mathrm{~min}$ and 0.001 at 90,120 and $180 \mathrm{~min}$. Baseline excluded for subsequent multiple comparisons. $P$ (before correction $)=0.004$ for aspirin versus control at all time points except baseline. $P$ (before correction $)=0.337$ between control and piperine groups at 60 min; 0.054 at $90 \mathrm{~min}, 0.004$ at $120 \mathrm{~min}$, and 0.20 at $180 \mathrm{~min} . P$ (before correction) $=0.037$ between aspirin and piperine groups at $60 \mathrm{~min} ; 0.004$ at 90,120 , and $180 \mathrm{~min}$. $P$ values based on actual latency period in seconds and statistical significance for multiple comparisons after Bonferroni's correction is set at $P<0.017$. SD: Standard deviation; \%MPE: Percentage maximum possible effect

Table 3: Effect of test substances on paw volume in carrageenan-induced paw edema in rats

\begin{tabular}{|c|c|c|c|c|}
\hline \multirow[t]{2}{*}{$\begin{array}{l}\text { Groups } \\
\text { ( } n=6 / \text { group) }\end{array}$} & \multicolumn{4}{|c|}{$\begin{array}{l}\text { Paw volume ( } \mathrm{ml} \text { ) (percentage inhibition of edema), } \\
\text { mean } \pm \text { SD }\end{array}$} \\
\hline & At baseline & At $1 \mathrm{~h}$ & At $2 \mathrm{~h}$ & At $3 h^{*}$ \\
\hline Control & $0.92 \pm 0.16(\%)$ & $1.33 \pm 0.17$ & $2.36 \pm 0.44$ & $3.47 \pm 0.27$ \\
\hline Aspirin & $0.97 \pm 0.15$ & $1.09 \pm 0.07$ & $1.22 \pm 0.12$ & $1.33 \pm 0.07$ \\
\hline Piperine & $0.89 \pm 0.09$ & $1.15 \pm 0.08$ & $1.53 \pm 0.07$ & $1.59 \pm 0.05$ \\
\hline
\end{tabular}

${ }^{\star}$ The percentage inhibition at $3 \mathrm{~h}$ was $61.57 \%$ for aspirin group and $55.81 \%$ for piperine group when compared with the control group. $P=0.720$ between all 3 groups at baseline; 0.032 at $1 \mathrm{~h} ; 0.001$ at $2 \mathrm{~h}$; and $<0.001$ at $3 \mathrm{~h}$. Baseline excluded for subsequent multiple comparisons. $P$ (before correction $)=0.035$ between control and aspirin group at $1 \mathrm{~h} ; 0.004$ at $2 \mathrm{~h}$ and $3 \mathrm{~h} . P$ (before correction) $=0.050$ between control and piperine group at $1 \mathrm{~h} ; 0.004$ at $2 \mathrm{~h}$ and 3 h. $P$ (before correction) $=0.101$ between aspirin and piperine group at $1 \mathrm{~h} ; 0.051$ at $2 \mathrm{~h}$; and 0.004 at $3 \mathrm{~h}$. Statistical significance for multiple comparisons after Bonferroni's correction is set at $P<0.017$. SD: Standard deviation

aspirin, and piperine groups $(P<0.001)$. Percentage anti-inflammatory effect in comparison to the control group was $65.98 \%$ for the aspirin group $(P=0.003)$ and $39.42 \%$ for the piperine group $(P=0.004)$ where the new significance level after Bonferroni's correction is set at $P<0.017$. The mean difference in LCS between days 1 and 10 was significantly lower for the aspirin group when compared to the piperine group $(P=0.003$, before correction).

\section{Antipyretic effect}

Table 4 shows the rectal temperature of the rats used in the Baker's yeast pyrexia model at various time points. In all the three groups, there was a consistent rise in rectal temperature during the 4 -h period time till the test substances were administered $(P=0.028$ in each of the three groups), and at $0 \mathrm{~h}$, there was no difference between the groups in rectal temperature $(P=0.961)$. Piperine significantly reduced rectal temperature only at $4 \mathrm{~h}$ when compared with control, while aspirin reduced only at 3 and $4 \mathrm{~h}$. However, aspirin reduced rectal temperature significantly than piperine at both 3 and $4 \mathrm{~h}$.

\section{DISCUSSION}

The Indian traditional systems of medicine, especially Ayurveda and Siddha, is primarily plant-based systems which over time has gained a vast area for research and development because of their natural sources of origin as against the allopathic medicines. Hence, this study, evaluating the analgesic, anti-inflammatory, and antipyretic activity of the natural constituent of $P$. nigrum also called "the king of spices" gains significant importance. ${ }^{[12]}$
In the present study, we find that piperine has significant analgesic activity in all the three models of analgesia used. However, at a few time points, aspirin was significantly better than piperine. In the tail-flick model, which mainly evaluates the analgesic activity of centrally active drugs, ${ }^{[10]}$ we find that tramadol that acts centrally has the maximum effect, and thus, we find both aspirin and piperine to have a significantly lesser effect than tramadol. However, a study by Bukhari et al. ${ }^{[13]}$ has reported that piperine at $50 \mathrm{mg} / \mathrm{kg}$ IP showed significant analgesic activity, similar to that produced by morphine, which was further abolished by naloxone, an opioid antagonist, suggesting that piperine acts through opioid receptors. This difference in the finding in our study may be attributed to the oral route of administration without using a higher dose above $50 \mathrm{mg} / \mathrm{kg}$ that was used IP in the previous study. A study by Sabina et al. evaluating the analgesic effect of piperine at $30 \mathrm{mg} / \mathrm{kg}$ IP using hot plate model in mice reports a significant analgesic effect but much less than the standard indomethacin group, thus confirming the centrally mediated action of piperine. ${ }^{[14]}$ Our study results also corroborate these findings. Tasleem et al. have reported that piperine $15 \mathrm{mg} / \mathrm{kg}$ IP showed the percentage of inhibition of writhing by $100 \% .{ }^{[15]}$ However, we have reported a percentage inhibition of only about $50 \%$. This is probably due to the different routes of administration. Our findings, however, are similar to those reported in the study by Sabina et al., ${ }^{[14]}$ where they have also not reported complete inhibition of writhing in acetic acid mice model.

With regard to anti-inflammatory activity, we report that the percentage inhibition of acute inflammation in 56\% when compared to control and aspirin shows the highest percentage inhibition of $62 \%$ at $3 \mathrm{~h}$. These findings are similar to those reported by other studies. A study by Sireeratawong et al. using other species of Piper showed significant analgesic activity at $3 \mathrm{~h}^{[16]}$ Another study by Sudjarwo showed $54.8 \%$ inhibition of analgesia at $10 \mathrm{mg} / \mathrm{kg}$ IP dose. ${ }^{[17]}$ These results agree closely with nonsteroidal anti-inflammatory drugs, which act via the inhibition of the synthesis of prostaglandins in inflammation, ${ }^{[18]}$ suggesting that piperine also may act by similar mechanisms and thus corroborating the findings of the in vitro studies. ${ }^{[7]}$ In the cotton pellet-induced granuloma method that measures the activity against subacute inflammation and granuloma formation, we report that piperine did not significantly differ in activity from the control. In the study by Sireeratawong et al., ${ }^{[16]}$ we find that $P$. interruptum extract shows percentage inhibition of only $5 \%$ while that of $P$. chaba extract shows a significant reduction of $36 \%$; the difference attributed to the quantity of active ingredient present in each of these extracts. Hence, in our study, it is possible that the given oral dose was not sufficient to show significant effect though there is a trend toward a decrease in granuloma weight of approximately $10 \%$ when compared to the control. In the formalin-induced arthritis 
Table 4: Effect of test substances on rectal temperature in Baker's yeast-induced pyrexia model in rats

\begin{tabular}{|c|c|c|c|c|c|}
\hline \multirow{2}{*}{$\begin{array}{l}\text { Groups } \\
\text { (n=6/group) }\end{array}$} & \multicolumn{5}{|c|}{ Rectal temperature $\left({ }^{\circ} \mathrm{C}\right)$, mean $\pm \mathrm{SD}$} \\
\hline & At-4 h & At $0 \mathrm{~h}$ & At $3 \mathrm{~h}$ & At $4 \mathrm{~h}$ & At $6 \mathrm{~h}$ \\
\hline Con & $37.18 \pm 0.64$ & $38.27 \pm 0.27$ & $38.62 \pm 0.32$ & $38.98 \pm 0.22$ & $38.05 \pm 0.46$ \\
\hline Aspirin & $37.33 \pm 0.41$ & $38.57 \pm 0.32$ & $37.65 \pm 0.38$ & $37.77 \pm 0.38$ & $37.65 \pm 0.50$ \\
\hline Piperine & $37.23 \pm 0.31$ & $38.42 \pm 0.29$ & $38.43 \pm 0.25$ & $38.47 \pm 0.19$ & $38.22 \pm 0.20$ \\
\hline
\end{tabular}

$P$ (before correction) $=0.961$ between all 3 groups at $-4 \mathrm{~h} ; 0.323$ at $0 \mathrm{~h} ; 0.003$ at 3 $\mathrm{h} ; 0.001$ at $4 \mathrm{~h}$; and 0.148 at $6 \mathrm{~h} ;-4,0$, and $6 \mathrm{~h}$ excluded for subsequent multiple comparisons. $P$ (before correction) $=0.004$ between control and aspirin groups at $3 \mathrm{~h}$ and $4 \mathrm{~h} . P$ (before correction $)=0.334$ between control and piperine groups at $3 \mathrm{~h} ; 0.005$ at $4 \mathrm{~h} . P$ (before correction) $=0.005$ between aspirin and piperine group at $3 \mathrm{~h} ; 0.008$ at $4 \mathrm{~h}$. Statistical significance for multiple comparisons after Bonferroni's correction is set at $P<0.017$. SD: Standard deviation

model of chronic inflammation, we report that both aspirin and piperine have a significant anti-inflammatory effect. These findings corroborate the in vitro studies published earlier. ${ }^{[7,19]}$ However, aspirin continues to be significantly superior when compared to piperine.

With regard to antipyretic effect, we report that piperine significantly reduces fever at $4 \mathrm{~h}$ when compared to the controls. At $3 \mathrm{~h}$, there was a reduction in rectal temperature, but it did not achieve statistical significance probably due to small sample size. These findings were similar to the results published by Sabina et al., who reported a dose-dependent reduction in fever comparable to indomethacin. ${ }^{[14]}$ On the other hand, aspirin proved to have the maximal effect, and the temperature reduction was much higher than piperine at both 3 and $4 \mathrm{~h}$. Further studies with higher oral doses of piperine may throw light if it would be comparable in effect to aspirin. Further, studies focusing on co-administration of piperine with another anti-inflammatory, antipyretic, or analgesic would go a long way in tapping the maximum benefit out of piperine. ${ }^{[20]}$ At $6 \mathrm{~h}$, however, there was no difference among all three groups possible due to the wearing a way of the effect of exogenous pyrogens.

\section{CONCLUSION}

We report that oral piperine administration has shown significant analgesic effect when compared to control, though not comparable to aspirin. The anti-inflammatory effects have been proved with carrageenan-induced paw edema method of acute inflammation and formalin-induced arthritis model of chronic inflammation, although it failed to prove statistical significance in the cotton pellet-induced granuloma method of subacute inflammation. This warrants further studies with various higher doses of orally administered piperine as systemic administration in other studies has proved the efficacy of piperine as a potent anti-inflammatory. Piperine also shows fever reducing activity when compared to controls, but aspirin significantly lowers rectal temperature than piperine. In conclusion, we state that piperine could be a potential analgesic, anti-inflammatory, and antipyretic, which requires further evaluation with studies using varying oral doses, higher animals, and in combination with various other analgesics, anti-inflammatory, and antipyretic agents.

\section{Acknowledgements}

We would like to acknowledge Dr. Vijay Motghare, Professor and Head, Department of Pharmacology, Government Medical College, Nagpur, for his inputs during the protocol development. We would also like to acknowledge Unijules Life Sciences Limited, Nagpur, for providing us with the piperine extract.

\section{Financial support and sponsorship}

Nil.

\section{Conflicts of interest}

There are no conflicts of interest.

\section{REFERENCES}

1. Robbins SL, Cotron RS. Acute and chronic inflammation. In: Kumar V, Abbas AK, Fausto N, editors. Pathologic Basis of Disease. $9^{\text {th }}$ ed. Philadelphia: Elsevier Publications; 2013. p. 29-72.

2. Treede RD. The international association for the study of pain definition of pain: As valid in 2018 as in 1979, but in need of regularly updated footnotes. Pain Rep 2018;3:e643.

3. Dalal S, Zhukovsky DS. Pathophysiology and management of fever. J Support Oncol 2006;4:9-16.

4. Hayliyar J, Macpherson A, Bjarnason I. Gastro protection and nonsteroidal anti-inflammatory drugs. Drug Saf 1992;4:1323-6.

5. Bhardwaj RK, Glaeser H, Becquemont L, Klotz U, Gupta SK, Fromm MF. Piperine, a major constituent of black pepper, inhibits human P-glycoprotein and CYP3A4. J Pharmacol Exp Ther 2002;302:645-50.

6. Pei YQ. A review of pharmacology and clinical use of piperine and its derivatives. Epilepsia 1983;24:177-82.

7. Stöhr JR, Xiao PG, Bauer R. Constituents of Chinese Piper species and their inhibitory activity on prostaglandin and leukotriene biosynthesis in vitro. J Ethnopharmacol 2001;75:133-9.

8. Fu M, Sun ZH, Zuo HC. Neuroprotective effect of piperine on primarily cultured hippocampal neurons. Biol Pharm Bull 2010;33:598-603.

9. Vogel HG. Discovery and Evaluation Pharmacological Assays. $2^{\text {nd }}$ ed. Germany: Springe; 2008. p. 1120-64

10. D'Amour FE, Smith DL. A method for determining loss of pain sensation. J Pharmacol Exp Ther 1941;72:74-9.

11. Winter CA, Risley EA, Nuss GW. Carrageenin-induced edema in hind paw of the rat as an assay for antiiflammatory drugs. Proc Soc Exp Biol Med 1962;111:544-7.

12. Damanhouri ZA, Ahmad A. A review on therapeutic potential of Piper nigrum L. (Black Pepper): The King of Spices. Med Aromat Plants 2014;3:161.

13. Bukhari IA, Pivac N, Alhumayyd MS, Mahesar AL, Gilani AH. The analgesic and anticonvulsant effects of piperine in mice. J Physiol Pharmacol 2013;64:789-94.

14. Sabina EP, Nasreen A, Vedi M, Rasool M. Analgesic, antipyretic and ulcerogenic effects of piperine: An active ingredient of pepper. J Pharm Sci Res 2013;5:203-6.

15. Tasleem F, Azhar I, Ali SN, Perveen S, Mahmood ZA. Analgesic and anti-inflammatory activities of Piper nigrum L. Asian Pac J Trop Med 2014;7S1:S461-8.

16. Sireeratawong $S$, Itharat $A$, Lerdvuthisopon $N$, Piyabhan $P_{\text {, Khonsung }} P_{t}$ Boonraeng $S$, et al. Anti-inflammatory, analgesic, and antipyretic activities of the ethanol extract of Piper interruptum Opiz. and Piper chaba Linn. ISRN Pharmacol 2012;2012:480265

17. Sudjarwo SA. The potency of piperine as anti-inflammatory and analgesic in rats and mice. Folia Med Indones 2005;41:190-4.

18. Smith JB, Willis AL. Aspirin selectively inhibits prostaglandin production in human platelets. Nat New Biol 1971;231:235-7.

19. Bang JS, Oh DH, Choi HM, Sur BJ, Lim SJ, Kim JY, et al. Anti-inflammatory and antiarthritic effects of piperine in human interleukin 1 beta-stimulated fibroblast-like synoviocytes and in rat arthritis models. Arthritis Res Ther 2009; 11:R49.

20. Gupta SK, Bansal P, Bhardwaj RK, Velpandian T. Comparative anti-nociceptive, anti-inflammatory and toxicity profile of nimesulide vs nimesulide and piperine combination. Pharmacol Res 2000;41:657-62. 